This document is confidential and is proprietary to the American Chemical Society and its authors. Do not copy or disclose without written permission. If you have received this item in error, notify the sender and delete all copies.

\title{
Vegetable oils de-acidification by methanol heterogeneously catalyzed esterification in (monophasic liquid)/solid batch and continuous reactors
}

\begin{tabular}{|r|l|}
\hline Journal: & Energy \& Fuels \\
\hline Manuscript ID: & ef-2014-01397h.R1 \\
\hline Manuscript Type: & Article \\
\hline Date Submitted by the Author: & n/a \\
\hline Complete List of Authors: & $\begin{array}{l}\text { Pirola, Carlo; Università degli Studi di Milano, Dipartimento di Chimica } \\
\text { Galli, Federico; Università degli Studi di Milano, Dipartimento di Chimica } \\
\text { Bianchi, Claudia; Università degli Studi di Milano, Dipartimento di Chimica } \\
\text { Boffito, Daria Camilla; Polytechnique Montreal, Chemical Engineerinf } \\
\text { Department } \\
\text { Comazzi, Alberto; Università degli Studi di Milano, Dipartimento di Chimica } \\
\text { Manenti, Flavio; Politecnico di Milano, CMIC }\end{array}$ \\
\hline
\end{tabular}

SCHOLARONE

Manuscripts 


\title{
Vegetable oils de-acidification by methanol heterogeneously catalyzed esterification in (monophasic liquid)/solid batch and continuous
} reactors.

Carlo Pirola ${ }^{\diamond}$, Federico Galli ${ }^{\diamond,}$, Claudia L. Bianchi ${ }^{\diamond}$, Daria C. Boffito

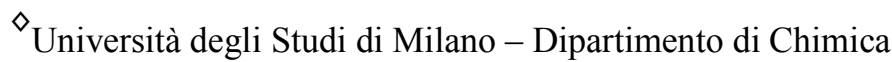

via Golgi 19 - 20133 Milano (Italy)

${ }^{+}$Politecnico di Milano - Dipartimento di Chimica, Materiali e Ingegneria Chimica "Giulio Natta"

Piazza Leonardo da Vinci, 32 - 20133 Milano, Italy

\#École Polytechnique de Montréal - Département de Génie Chimique

2900, boul. Édouard-Montpetit, Montréal (QC), Canada

\author{
*To whom correspondence should be addressed \\ Tel: ++39/0250314293; Fax: ++39/0250314300 \\ E-mail: carlo.pirola@unimi.it
}




\begin{abstract}
The removal of FFA in vegetable oils is an important pre-treatment in the production of biodiesel, in particular when the starting materials are low cost feedstocks. Heterogeneouslycatalysed esterification with methanol transforms FFA in FAME, decreasing the oil acidity and producing biodiesel simultaneously. The equilibrium of this reaction shifts towards the desired product when increasing the methanol content but, at the same time, a double liquid phase system forms when the methanol content is higher than $6-8 \% \mathrm{wt}_{\mathrm{wt}}$. The presence of a double liquid phase can be an important drawback in the reactor. A detailed study about the optimization of the methanol quantity is presented, both using a batch and a packed bed reactor (PBR) at different temperatures (between 60 and $105^{\circ} \mathrm{C}$ ) using Amberlyst 46 (ion exchange resin) as heterogeneous catalyst. The deacidification of sunflower oil in a monophasic liquid system leads to satisfactory results (final FFA lower than $0.5 \%_{\mathrm{wt}}$ ) for both the reactors. The experimental results demonstrate that the excess of methanol is not convenient in terms of both slower reaction rates and mass of reactant used. The stability of Amberlyst 46 in PBR reactor was positively verified after 600 h of work.
\end{abstract}

Keywords: vegetable oil deacidification, methanol, ion exchange resin, monophasic system, PBR 


\section{Introduction}

Biofuels are imposing themselves as key products for the sustainability of the World energy demand in the forthcoming years. Biodiesel in particular is a non-toxic, biodegradable, environmentally friendly fuel ${ }^{1}$. Biodiesel is a fatty acid methyl esters (FAME) mixture obtained by the transesterification of highly refined vegetable oils with methanol by homogeneously- catalysed processes $^{2-4}$. Triglycerides (about 90-98\%) and free fatty acids (FFA) in the C10-C22 range, with different unstauration levels, compose the raw materials. Currently, the main problem of the commercialization of biodiesel is its final cost, that strongly depends on the feedstock used (about $85 \%$ of the total $)^{5}$.

Feedstocks such as not refined or waste oils represent a very convenient choice in order to lower biodiesel production costs. Some examples of low cost raw materials for biodiesel production are crude vegetable oil ${ }^{4}$, waste cooking oil ${ }^{1}$ and animal fat ${ }^{6}$. The main problem associated with the use of low-cost feedstocks lies in their high content of FFA, leading to the formation of soaps during the transesterification. Esterification of FFA in presence of either homogeneous or heterogeneous acid catalysts allows, at the same time, to lower the acid content and to obtain methyl esters, i.e. biodiesel, already in this preliminary step; a remarkable advantage of heterogeneous catalysis is the easier separation and recovery of the catalyst after the reaction. Sulphonic acid exchange resins ${ }^{5-10}$ are among the most widely adopted catalysts in the FFA esterification. Sulphonic acid exchange resins are characterized by a gel structure of microspheres that forms a macroporous polymer (generally copolymers of divinylbenzene and styrene) with sulphonic Brønsted acid groups as active sites.

In the deacidification process by esterification, although the stoichiometric alcohol/FFA molar ratio is one, a higher amount of alcohol is convenient in order to shift the reaction towards the desired products. For this reason, in the typical reaction conditions ${ }^{8,11-12}$ there are two liquid phases, being the methanol soluble in oil up to about $6-8 \%$ by weight, depending on the operative conditions and on the oil type. The presence of a double liquid phase (plus the solid catalyst) makes 
much more difficult the design and operation of the different types of reactors, either batch or continuous, for different reasons. First of all, the second liquid phase, consisting of the excess of methanol, extracts part of the FFA from the oil phase. This extraction contributes to the deacidification of the oil, but does not form FAME, resulting in a loss of the final product. Moreover, in continuous reactors, in particular packed bed reactors, the part of the catalyst particles surrounded by the methanol phase is physically not in contact with the FFA of the vegetable oil, and cannot therefore extert its action. This means that a consistent part of the catalytic bed is excluded from the reaction. Finally, a liquid-liquid-solid system is more complex from a diffusional point of view, being highly mass transfer limited.

The aim of the present work is to study the effect of the oil/methanol ratio in this kind of systems, with particular attention to the formation of the second methanol-rich liquid phase. We use a particular kind of sulphonic acid exchange resin: Amberlyst 46 (A46). The choice of this resin was based on its peculiar properties; in fact, unlike all the other Amberlyst type of resins, this catalyst is not internally sulphonated but it only has surface acid groups ${ }^{8}$. Consequently, it is not subject to any internal adsorption-desorption phenomena for both reactants and products. This catalyst was used by the Authors in a previous work ${ }^{13}$, where its performance and durability were very satisfactory. In the same study the problems due to the presence of a liquid-liquid-solid system in the reactor were highlighted and partially solved using an emulsificator device.

In the present paper, we study the possibility and show the advantages of working with a limited amount of methanol, and consequently to operate in a (monophasic liquid)/solid system in batch and continuous reactors.

\section{Experimental}

Sunflower oil was purchased from TopAgri (Verona, Italy). Palmitic acid (>98\%) and methanol (>99.8\%) were purchased from Sigma Aldrich and $\mathrm{KOH} 0.1 \mathrm{molL}^{-1}$ in ethanol was purchased from Fluka. 
Amberlyst 46 (wet) catalyst was used for all the experiments. It was kindly provided by Dow Chemicals. Table $1^{8}$ summarizes the main features of this resin.

Before the use, Amberlyst 46 was dried at $80^{\circ} \mathrm{C}$ in an oven for $14-16$ hours. Higher temperatures in air atmosphere are not recommended, due to the risk of losing the sulphonic acid sites in the form of $-\mathrm{SO}_{3} \mathrm{H}$ (desulfurization of the polystyrene matrix of the catalyst). Differently, when the catalyst works in liquid phase, the maximum operating temperature specified by the manufacturer is $120^{\circ} \mathrm{C}$, as reported in Table 1 .

The exchange capacity of the catalyst in its wet form was evaluated by total ion exchange with sodium chloride solution and subsequent titration ${ }^{10}$. A value of $0.43 \pm 0.01 \mathrm{meq} \mathrm{g}^{-1}$ was obtained, which is consistent with the manufacturer data.

The determination of the FFA weight percentage was carried out using a colorimetric titration $^{6}$. In both the case of one and two liquid phases, an amount of oil was withdrawn from the reactor after stopping the stirring for 1 minute. $20 \mathrm{~mL}$ of 2-propanol was added to each sample to dissolve FFA and facilitate the titration. $\mathrm{KOH} 0.1 \mathrm{molL}^{-1}$ was used as titrant and phenolphthalein as indicator. FFA weight percentage was calculated using the following equation:

$$
F F A\left[\%_{W}\right]=\frac{\text { Volume }_{\text {titrant }}[L] * 0.1\left[\frac{\mathrm{mol}}{\mathrm{L}}\right] * \overline{M W_{F F A}}\left[\frac{\mathrm{g}}{\mathrm{mol}}\right]}{\text { sample mass }[\mathrm{g}]}
$$

where $\overline{M W_{F F A}}$ was calculated considering both the original FFA composition of sunflower oil and the initial addiction of palmitic acid (see paragraph 2.1). The value of residual acidity is compared to the initial value, and the acidity conversion \% was calculated as follows:

$$
F F A_{\text {conversion }}[\%]=\frac{F F A_{0}-F F A_{t}}{F F A_{0}} * 100
$$

where, $\mathrm{FFA}_{0}$ is the initial acid value, and $\mathrm{FFA}_{\mathrm{t}}$ is the acid value at time $\mathrm{t}$.

Fresh catalyst, corresponding to $10 \%{ }_{\mathrm{w}}$ of oil was used in all the tests.

\subsection{Liquid-liquid-solid and (monophasic liquid)-solid batch experiments}


All the experimental data were gathered using a 3-necked $500 \mathrm{~mL}$ batch reactor (Figure 1a), equipped with a thermometer, a reflux condenser, to avoid loss of volatile compounds and a mechanical stirrer, in order to control in a very accurate way the agitation speed. The thermostatic oil bath maintained the reaction temperature constant. The protocol followed for all the experiments was: a) charge about $200 \mathrm{~g}$ of sunflower oil; b) add about $5 \mathrm{~g}$ of palmitic acid in order to bring the acidity to a value around $3 \%_{\mathrm{wt}}$; c) start the agitation and the heating to facilitate the palmitic acid dissolution; d) determine the initial FFA weight content as discussed above; e) add $10 \%_{\mathrm{wt}}$ of catalyst; f) add the methanol after the achievement of the temperature set. This point was considered as time zero of the reaction.

Eleven different tests in batch, all at atmospheric pressure were performed and are summarized in Table 2. In particular, in the RUNS 1-3 the influence of agitation speed on the reaction was evaluated from 100 to $300 \mathrm{rpm}$, in order to avoid external diffusional limitations in the subsequent experiments. In RUN 4, no catalyst was used in order to study the FFA extraction phenomenon in the presence of two liquid phases. In the RUNS 5-11 different methanol/FFA mole ratio were tested. While in RUNS 5-9 only one liquid phase is present, in RUNS 10-11 there are two liquid phases, whereby the extraction phenomenon must be taken into account.

\section{2 (Monophasic liquid)-solid deacidification in a Packed Bed Reactor (PBR)}

Once the possibility to operate in a monophasic system was demonstrated, seven continuous esterification reactions were carried out in a packed bed reactor, using the experimental scheme reported in Figure $1 b$.

The reactor is a stainless steel cylinder $20.3 \mathrm{~cm}$ long, with an internal diameter of $4.7 \mathrm{~cm}$ with 3 intermediate sample ports. The catalytic bed, of $8 \mathrm{~cm}$ of height, is placed at $7.4 \mathrm{~cm}$ from the bottom of the reactor and it has a volume of $86 \mathrm{~cm}^{3}$; a thermocouple is placed in the middle of the bed to control the reactor temperature. Two sampling ports are located at 1.5 and $6.5 \mathrm{~cm}$ from the bottom of the bed, respectively. This configuration allows to collect three samples, corresponding to 
these intermediate points plus the final one, characterized by three different residence times in the PBR for a fixed flow. The experimental feed flow rates and calculated residence times are reported in Table 3. In order to maintain a constant internal temperature, we used an electrical resistance band controlled by an internal thermocouple. The temperature inside the reactor was controlled by a thermocouple inserted in the middle of the catalytic bed, with a precision of $1{ }^{\circ} \mathrm{C}$. The oil is mixed with methanol using a methanol:FFA molar ratio of 5:1 in a feeding chamber (FC) pressurized by compressed air at 6 bar. The feed is fluxed into the reactor, heated by an external hot circuit and insulated using glass fibers. The whole system is thus under the same pressure of the FC while the reactant flow is controlled by a mechanical valve (V7).

The esterification reaction tests were carried out at different operative temperatures, i.e. 54, $65,75,85,95$ and $105^{\circ} \mathrm{C}$ at 6 bar. The main advantage of this reactor configuration is the possibility to perform the reaction above the methanol normal boiling point $\left(64^{\circ} \mathrm{C}\right)$, because the system is under pressure. This means that the reaction is fastened both because the kinetic parameters are dependent on temperature and also because the solubility of methanol increases with temperature, which means that a higher methanol/FFA molar ratio can be used while avoiding the formation of the second phase. All the tests were repeated at least twice. The reaction at $75^{\circ} \mathrm{C}$ was repeated at the end of all the tests and compared with the one performed at the beginning of the experimental study with the fresh catalyst at the same temperature, with the aim of studying the catalyst stability.

\section{Results and Discussion}

As mentioned in the experimental part, the objective of RUNS 1-3 was to estimate the influence of the stirring rate on the FFA conversion in the esterification. Figure 2 reports the experimental results, expressed as FFA conversion vs. time of reaction. At all the conditions tested $(100,200$ and $300 \mathrm{rpm})$ the external diffusion does not influence the reaction rate. Therefore, all the subsequent experimental tests were performed at $100 \mathrm{rpm}$. 
The objective of RUN 4 was to estimate the extent of the FFA extraction by methanol. In this peculiar RUN, in fact, no catalyst was added and the samples to determine the FFA conversion were gathered from the oil phase after separation from methanol, i.e. only the FFA in the oil phase were quantified. After only 10 minutes about $23 \%$ of the initial FFA diffuse in the methanol phase at the condition used (Figure 3). Therefore, when two liquid phases are present, a not negligible quantity of FFA cannot be converted into FAME, as it is not in contact with the catalyst, but captured by the excess of methanol. In Figure 3 it is also reported the trend of the non-catalyzed FFA esterification performed in the batch reactor at $60^{\circ} \mathrm{C}$ in a monophasic mixture of oil and methanol. This experiment, was performed to highlight that the reaction rate of the reaction is too low to achieve appreciable FFA conversions, as already reported in literature ${ }^{13}$, showing that the use of a catalyst is necessary to perform the FFA esterification. Seven different batch esterification reactions were carried out changing the methanol/FFA molar ratio. In the last two runs (RUNS 1011) the methanol was enough to create two liquid phases. Figure 4 summarizes the experimental data. At first sight it could be concluded that the higher the amount of methanol, the faster the esterification reaction. Differently, when a double phase system forms, the amount of methanol in the oil phase remains constant at a fixed temperature. As a consequence, the reaction rate maximizes and remains constant at any methanol/FFA molar ratio. While in the presence of one liquid phase the Le Châtelier principle is valid, in a two liquid system the extraction of FFA by the second phase (excess of methanol) must be taken into account. In Figure 5 it is shown a comparison with the experimental data of RUN 10 without considering the FFA dissolution in the methanol phase and considering it by calculating the real FFA amount, i.e. dividing the experimental data (which represent the FFA amount in the oil phase) by the extraction percentage (24\%). In particular, the first sample analysis reports an actual conversion of $43.15 \%$, which is consistent with the data of RUN 9, where methanol is more than 9 times lower (about $11.5 \mathrm{~g}$ for RUN 9 against $107.3 \mathrm{~g}$ for RUN 10). All these data collected in a batch reactor demonstrate the possibility to perform the esterification reaction using limited amount of methanol, i.e. operating in a (monophasic 
liquid)/solid system. The disadvantages of a slower reaction rate with respect to biphasic liquid system (with higher amount of methanol) are in fact more than compensated by the advantages already discussed.

The experimental results collected in the PBR reactor, expressed as FFA conversion \% versus residence time, are reported in Figure 6. All these data were collected in a exclusively in a (monophasic liquid)/solid system. Correctly, only the slope of the first step is highly dependent on the temperature. It is noteworthy to observe that, also working with a quantity of methanol not so high to form a new liquid phase, the reaction results are very satisfactory.

In a previous paper ${ }^{14}$ the authors reported the results obtained with a liquid-liquid-solid PBR reactor operating with a double phase liquid system. In this work ${ }^{14}$ it was demonstrated the difficulty to have a double phase liquid system, due to the separation between the two phases occurring inside the tubular reactor with the significant loss of a part of the catalytic bed. In order to solve this problem, a great effort was made in order to obtain stable emulsions, by dividing the catalytic bed into two parts and inserting a mixing system in between them: either a simple mixing chamber or an emulsificator device. The emulsificator allowed to obtain a more stable methanol/oil emulsion, showing a remarkable increase in the FFA conversion if compared to the results obtained in absence of a mixing system.

The total FFA conversion obtained in this reactor was greatly dependent on the extraction phenomenon due to the presence of the second liquid phase. In any case, the contact time was not sufficient to obtain FFA conversions greater than $35 \%$, even considering the FFA extraction. A direct comparison between these results obtained in our previous work ${ }^{14}$ and those presented in this paper would be incorrect since the experimental parameters (kind and shape of PBR reactors, kind of vegetable oils, reactants contact time in the catalytic bed, feed flow, operating pressure and temperature) are completely different. Nevertheless, the use of a (monophasic liquid)/solid system allows to reach very satisfactory FFA conversions suitable for the successive transesterification step in biodiesel production. Depending on the reactor temperature and reactants residence time in the 
catalytic bed, the FFA esterification reached in fact the thermodynamic plateau, corresponding to FFA conversion greater than $90 \%$. This means that the final FFA concentration in the oil was about $0.3 \%_{\mathrm{wt}}$, lower than the set limit of $0.5 \%$ for biodiesel processes production.

The catalyst deactivation and decay with time are crucial issues for the industrial application. In a previous paper ${ }^{14}$ the authors observed a loss of activity equal to $25 \%$ after $540 \mathrm{~h}$ $\left(\mathrm{T}=65^{\circ} \mathrm{C}\right)$ in a batch slurry reactor. Catalyst particles fragmentation occurred as a consequence of mechanical stirring and the catalyst powder so formed was inevitably lost in the batch reactor discharge operations between two successive runs. In the present work, the use of a packed bed of catalyst particles in the continuous reactor has solved this problem. In Fig. 6 we report a comparison between two runs in the PBR conducted exactly at the same operative conditions $\left(\mathrm{T}=75^{\circ} \mathrm{C} ; \mathrm{P}=6\right.$ bar): (1) "Fresh continuous run": conducted by using a fresh sample of catalyst; (2) "600 h continuous run": conducted by using the same catalyst of (1) but after about $600 \mathrm{~h}$ of work; more in detail this catalyst is the one used for all the continuous runs reported in this paper and it was never discharged from the PBR reactor.

These two runs overlap perfectly demonstrating in this way the maintenance of the catalyst activity by using the PBR reactor configuration, in agreement with the results reported in literature $^{15}$

No problems due to extraction or liquid phase separation (the reaction produces water, too) was observed and any additional tool (such as emulsificator or mixing chamber) was added to the plant before the catalytic reactor.

\section{$\underline{\text { 4. Conclusions }}$}

The esterification of FFA in sunflower oil with methanol was studied with particular reference to the amount of methanol used in the reaction. It is demonstrated that the formation of two liquid phases involves the dissolution of FFA in this second phase and this phenomenon has a slowing effect on the reaction due to the sequestration of FFA in the methanol phase. The 
experimental results demonstrate that the use of an excess of methanol is not convenient both in terms of slower reaction rates and mass of reactant used, whether the reaction takes place in a batch or in a continuous reactor. The PBR reactor configuration allows to maintain the same catalyst activity after more than $600 \mathrm{~h}$ of operation.

\section{Acknowledgments}

The Authors gratefully acknowledge financially support by the Italian Ministero delle Politiche Agricole, Alimetari e Forestali (project SUSBIOFUEL - D.M. 27800/7303/09). 


\section{References:}

(1) Pinto, A. C.; Guariero, L. L. N.; Rezende, M. J. C.; Ribeiro, N. M.; Torres, E. A.; Lopes, W. A.; Pereira, P. A. P.; Andrade J. B. J. Braz. Chem. Soc. 2005, 16B, 1313-1330.

(2) Ma, F. R.; Hanna, M. A. Bioresour. Technol. 1999, 70, 1-15.

(3) Fukuda, H.; Kondo, A.; Noda, H. J. Biosci. Bioeng. 2001, 92, 405-416.

(4) Canakci, M.; Sanli, H. J. Ind. Microbiol. Biotechnol. 2008, 35, 431-441.

(5) Tesser, R.; Di Serio, M.; Casale, L.; Sannino, L.; Ledda, M.; Santacesaria, E. Chem Eng. J. 2010, 161, 212-222.

(6) Bianchi, C. L.; Boffito, D. C.; Pirola, C.; Ragaini, V. Catal. Lett. 2009, 134, 179-183.

(7) Alexandros, S. D. Ind. Eng. Chem. Res. 2009, 48, 388-398.

(8) Chakrabarti, A.; Sharma, M. M. React. Polym. 1993, 20, 1-45.

(9) Boffito, D.C.; Pirola, C.; Galli, F.; Di Michele, A.; Bianchi, C.L. Fuel. 2013, 108, 612-619.

(10) Boffito, D.C.; Pirola, C.; Bianchi, C.L. Chemistry today. 2012, 30, $42-47$.

(11) Son, S. M.; Kimura, H.; Kusakabe, K. Bioresour. Technol. 2011, 102, 2130-2132.

(12) Santacesaria, E.; Tesser, R.; Di Serio, M.; Guida, M.; Gaetano, D.; Garcia, A. Ind. Eng. Chem. Res. 2007, 46, 5113-5121.

(13) Berrios, M.; Siles, J.; Martín, M.A.; Martín, A. Fuel. 2007, 86, 2383-2388.

(14) Pirola, C.; Bianchi, C. L.; Boffito, D. C.; Carvoli, G.; Ragaini V. Ind. Eng Chem Res. 2010, 49, 4601-4606.

(15) Feng, Y.; Zhang, A.; Li, J.; He, B. Bioresour. Technol. 2011, 102, 3607-3609. 


\section{Figure Captions}

Figure 1: Scheme of the a) batch reactor and b) PBR reactor used for batch and continuous esterification experiments respectively.

Figure 2: Experimental FFA conversion at different stirring rates, $\bullet 100 \mathrm{rpm}(\mathrm{RUN} 1), \bullet 200 \mathrm{rpm}$ (RUN 2) and $\boldsymbol{\Delta} 300 \mathrm{rpm}(\mathrm{RUN} 3)$.

Figure 3: Non catalyzed FFA esterification expressed as FFA percentage loss from the oil phase in function of time. Full points represent the monophasic liquid system (esterification), empty points the biphasic liquid system (esterification + extraction, RUN 4).

Figure 4: Experimental FFA conversion at different methanol/FFA molar ratios, + 1.96 (RUN 5), $2.99($ RUN 6), $\Delta 5.00($ RUN 7),$\bullet 10.06($ RUN 8), $13.38($ RUN 9),$\circ 94.32($ RUN 10) and $\square$ 149.35 (RUN 11). Full symbols indicate the present of only one liquid phase, empty ones the presence of two liquid phases.

Figure 5: Comparison between $\diamond$ experimental data of RUN 10 and $\downarrow$ the same data taking into account the extraction phenomenon.

Figure 6: experimental FFA conversion using a PBR in three different operative conditions: $\mathbf{a} 54^{\circ} \mathrm{C}$, - $65^{\circ} \mathrm{C},+75^{\circ} \mathrm{C}, \Delta 85^{\circ} \mathrm{C}, \bullet 95^{\circ} \mathrm{C}$ and $* 105^{\circ} \mathrm{C}$. $\circ$ represents the run repeated at $75^{\circ} \mathrm{C}$ after about 600 hours of work. 
Table 1: Catalyst A 46 main features.

\begin{tabular}{|c|c|c|c|c|c|}
\hline Catalyst & $\begin{array}{c}\text { Surface } \\
\text { Area } \\
\left(\mathrm{m}^{2} \mathrm{~g}^{-1}\right)\end{array}$ & $\begin{array}{c}\text { Average pore } \\
\text { Diameter } \\
(\AA)\end{array}$ & $\begin{array}{c}\text { Total pore } \\
\text { volume } \\
\left(\mathrm{mL} \mathrm{g}^{-1}\right)\end{array}$ & Acidity & $\begin{array}{c}\text { Max working } \\
\text { Temperature } \\
\left(\mathrm{meq} \mathrm{H}^{+} \mathrm{g}^{-1}\right)\end{array}$ \\
\hline Amberlyst 46 & 75 & 235 & 15 & $>0.4$ & 120 \\
\hline
\end{tabular}


Table 2: Summary of the batch experiments. $\mathrm{T}=59^{\circ} \mathrm{C}$.

\begin{tabular}{|c|c|c|c|c|c|c|c|}
\hline $\begin{array}{l}\text { RUN } \\
\text { number }\end{array}$ & $\begin{array}{l}\text { Liquid-solid (LS) } \\
\text { or Liquid-liquid- } \\
\text { solid (LLS) system }\end{array}$ & $\begin{array}{c}\mathrm{SO} \\
\text { mass }[\mathrm{g}]\end{array}$ & $\begin{array}{l}\mathrm{MeOH} \\
\text { mass [g] }\end{array}$ & $\begin{array}{l}\mathrm{FFA}_{0} \\
{\left[\% \%_{\mathrm{w}}\right]}\end{array}$ & $\begin{array}{c}\mathrm{MeOH} / \mathrm{FFA} \\
{[\mathrm{mol} / \mathrm{mol}]}\end{array}$ & $\begin{array}{c}\text { CATALYST } \\
\text { mass }[\mathrm{g}]\end{array}$ & $\begin{array}{c}\text { AGITATION } \\
\text { RATE } \\
{[\mathrm{rpm}]}\end{array}$ \\
\hline 1 & LS & 202.70 & 11.496 & 3.45 & 13.40 & 20.275 & 100 \\
\hline 2 & LS & 202.36 & 10.347 & 3.21 & 12.97 & 20.424 & 200 \\
\hline 3 & LS & 202.05 & 10.351 & 3.28 & 12.73 & 20.409 & 300 \\
\hline 4 & LLS & 202.50 & 74.002 & 3.22 & 92.49 & - & 100 \\
\hline 5 & LS & 201.57 & 1.546 & 3.19 & 1.96 & 20.308 & 100 \\
\hline 6 & LS & 202.33 & 2.262 & 3.05 & 2.99 & 20.411 & 100 \\
\hline 7 & $\overline{\mathrm{LS}}$ & 203.66 & 3.842 & 3.07 & 5.00 & 20.436 & 100 \\
\hline 8 & LS & 203.16 & 7.585 & 3.02 & 10.06 & 20.327 & 100 \\
\hline 9 & LS & 202.70 & 11.496 & 3.45 & 13.38 & 20.275 & 100 \\
\hline 10 & LLS & 203.32 & 70.320 & 2.99 & 94.32 & 20.419 & 100 \\
\hline 11 & LLS & 201.86 & 107.420 & 2.90 & 149.35 & 20.180 & 100 \\
\hline
\end{tabular}


Table 3: Operative flow rates and corresponding residence times in the PBR experimental runs at 54, 65, $95^{\circ} \mathrm{C}$, as example for all the runs reported in Fig. 6 .

\begin{tabular}{|c|c|c|c|c|c|}
\hline \multicolumn{2}{|c|}{$\mathrm{T}=54^{\circ} \mathrm{C}$} & \multicolumn{2}{|c|}{$\mathrm{T}=65^{\circ} \mathrm{C}$} & \multicolumn{2}{|c|}{$\mathrm{T}=95^{\circ} \mathrm{C}$} \\
\hline $\begin{array}{l}\text { Flow rate } \\
\left.(\mathrm{ml} \mathrm{min})^{-1}\right)\end{array}$ & $\begin{array}{l}\text { Residence } \\
\text { time (min) }\end{array}$ & $\begin{array}{l}\text { Flow rate } \\
\left.(\mathrm{ml} \mathrm{min})^{-1}\right)\end{array}$ & $\begin{array}{l}\text { Residence } \\
\text { time (min) }\end{array}$ & $\begin{array}{l}\text { Flow rate } \\
\left.(\mathrm{ml} \mathrm{min})^{-1}\right)\end{array}$ & $\begin{array}{l}\text { Residence } \\
\text { time (min) }\end{array}$ \\
\hline \multirow{3}{*}{0.27} & 17.4 & \multirow{3}{*}{0.26} & 18.1 & \multirow{3}{*}{0.24} & 19.6 \\
\hline & 262.4 & & 272.5 & & 295.2 \\
\hline & 318.5 & & 330.8 & & 358.3 \\
\hline \multirow{3}{*}{0.71} & 6.5 & \multirow{3}{*}{0.69} & 6.7 & \multirow{3}{*}{0.42} & 11.0 \\
\hline & 99.2 & & 102.1 & & 167.7 \\
\hline & 121.1 & & 124.6 & & 204.7 \\
\hline \multirow{3}{*}{1.35} & 3.5 & \multirow{3}{*}{1.39} & 3.4 & \multirow{3}{*}{0.91} & 5.2 \\
\hline & 52.5 & & 51.0 & & 77.8 \\
\hline & 63.7 & & 61.9 & & 94.5 \\
\hline & & & & \multirow{3}{*}{1.21} & 3.9 \\
\hline & & & & & 58.5 \\
\hline & & & & & 71.1 \\
\hline
\end{tabular}




\section{Page 17 of 22}

Figure 1
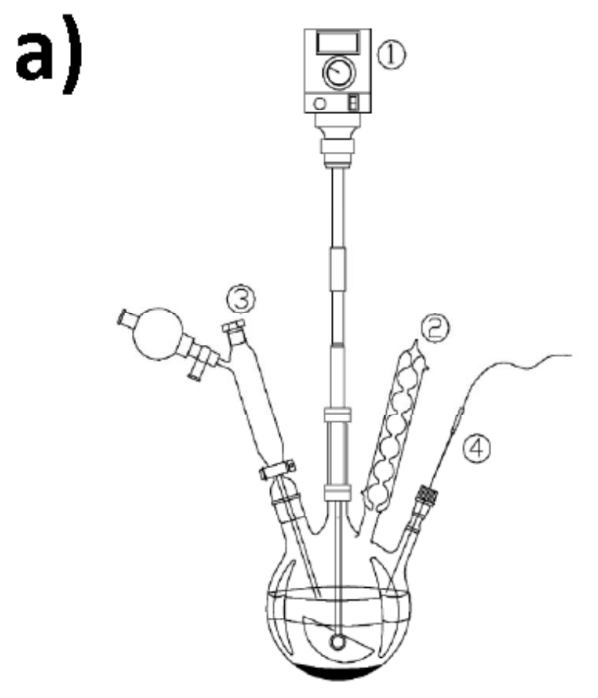

b)

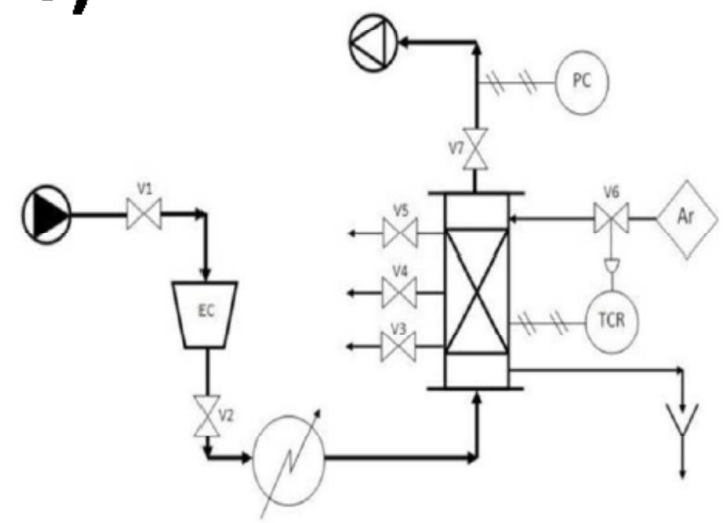


Figure 2

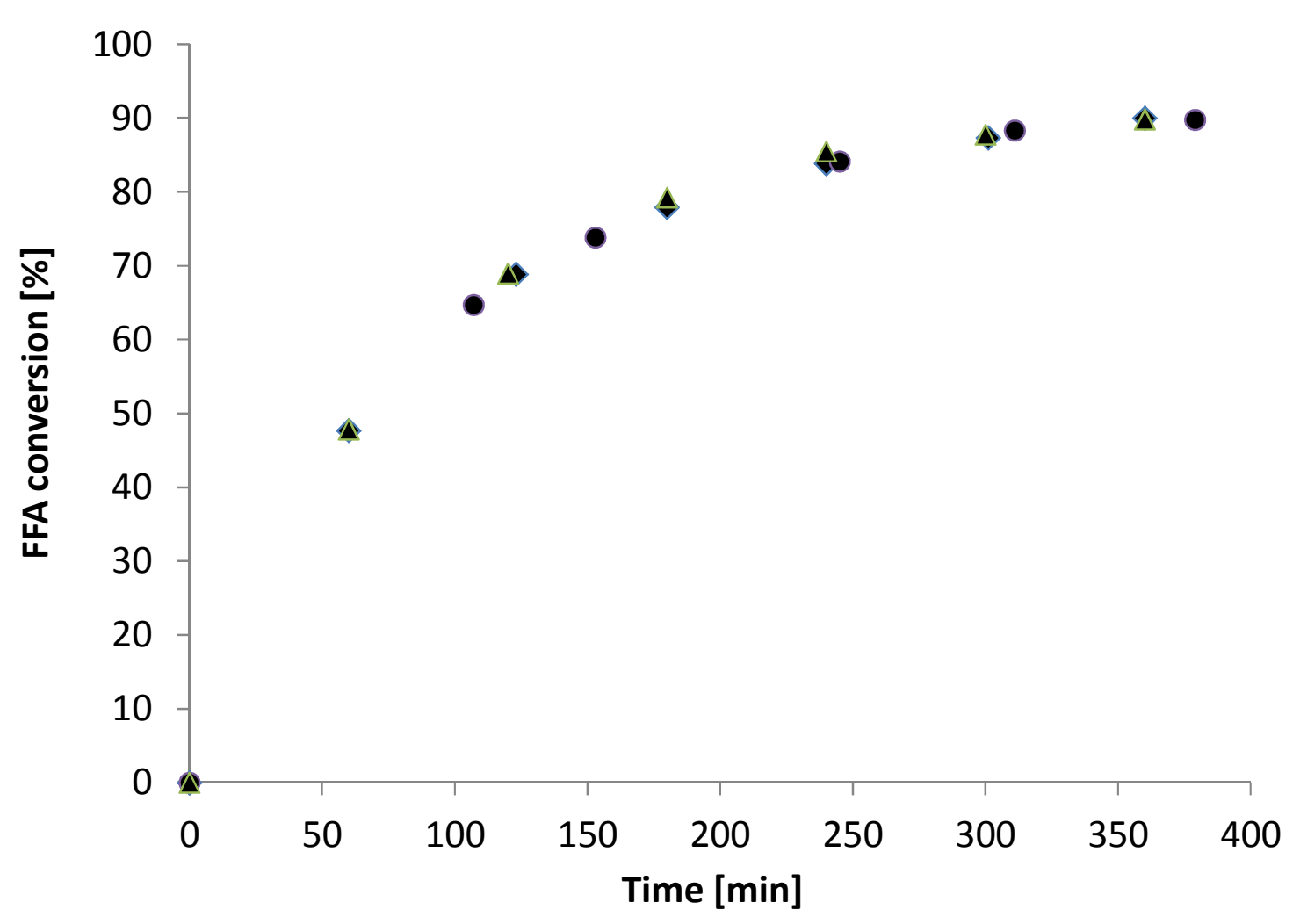

33

34

35

36

37

38

39

40

41

42

43

44

45

46

47

48

49

50

51

52

53

54

55

56

57

58

59

60 
Figure 3

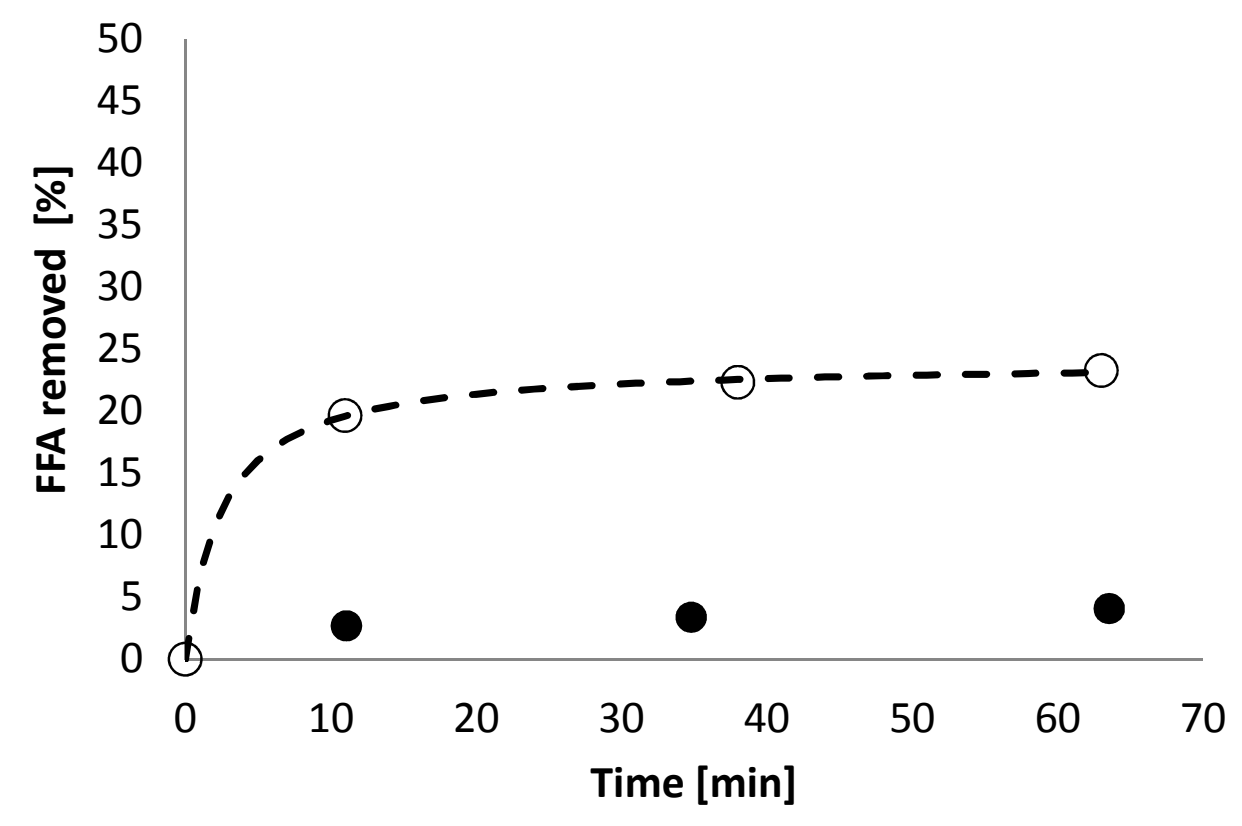


Figure 4

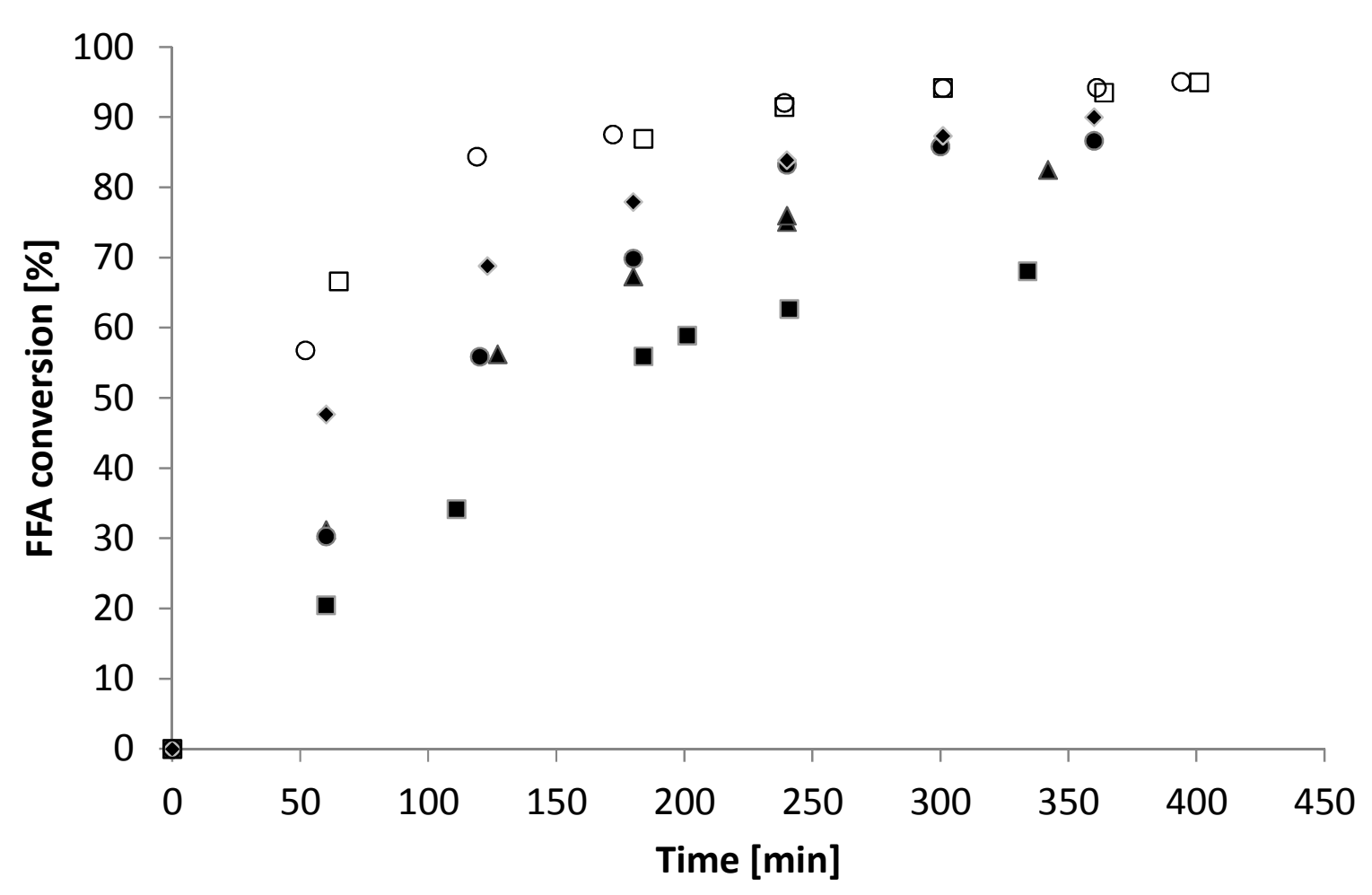

29 
Figure 5

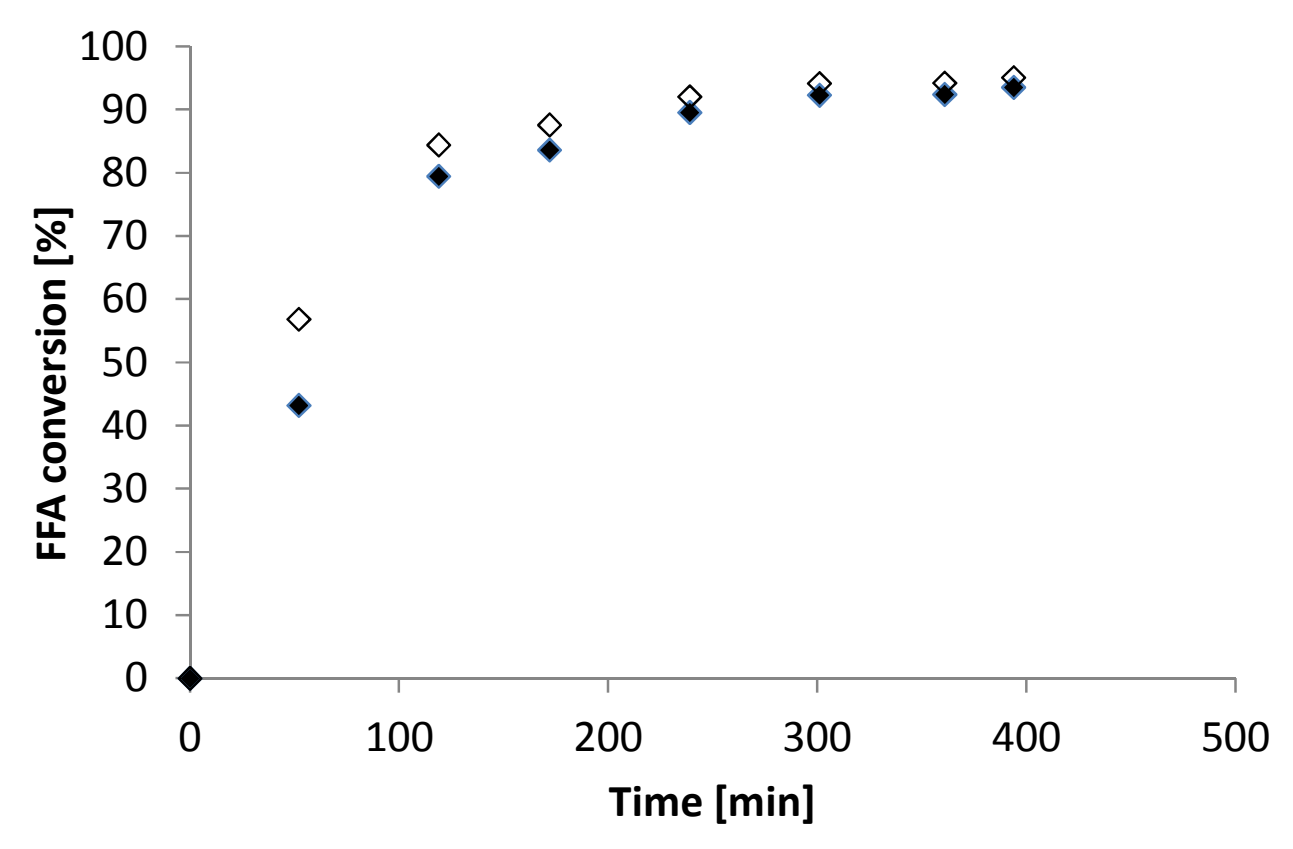

27

28

29

30

31

32

33

34

35

36

37

38

39

40

41

42

43

44

45

46

47

48

49

50

51

52

53

54

55

56

57

58

59

60 
Figure 6

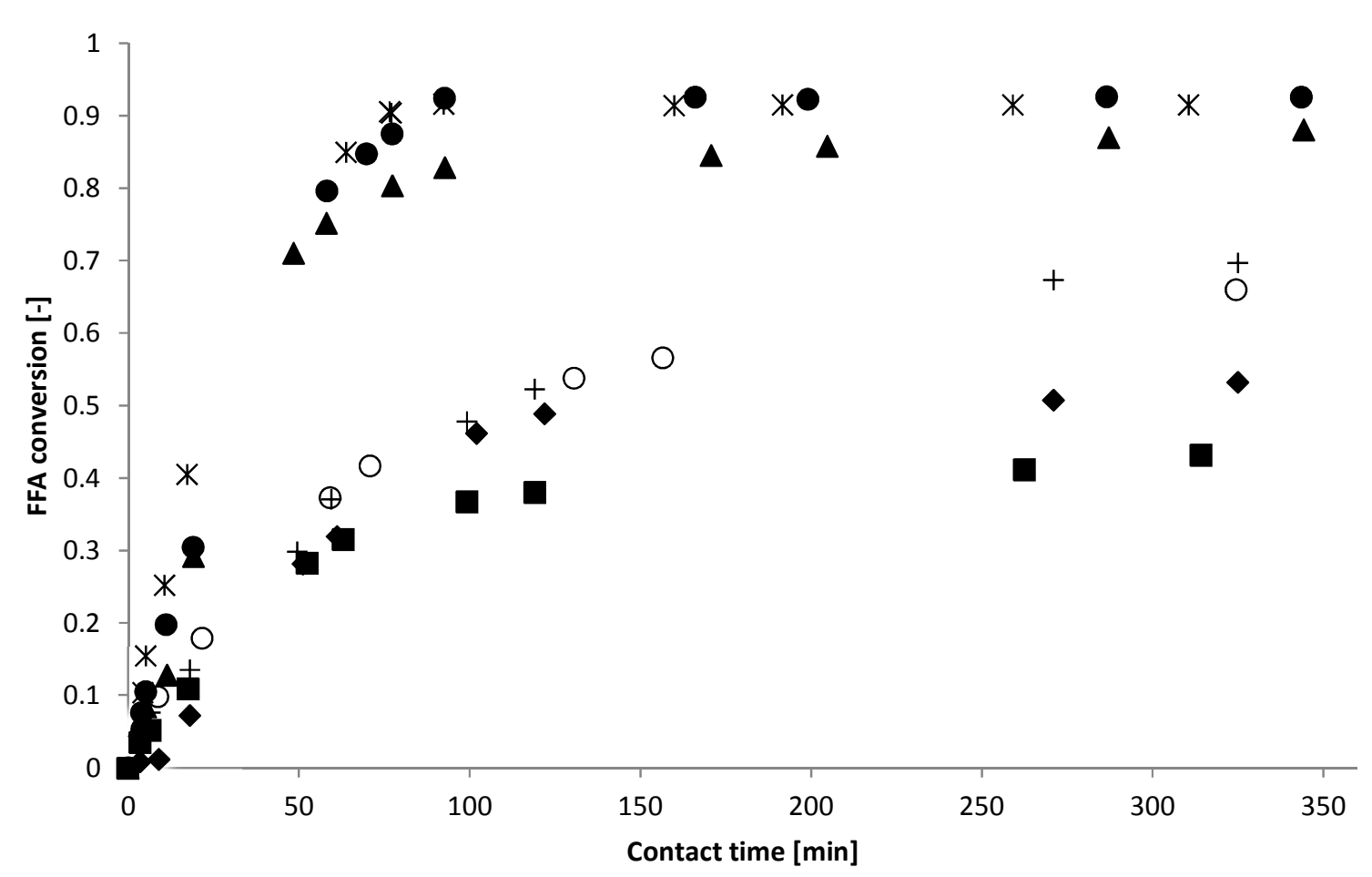

29

30

31

32

33

34

35

36

37

38

39

40

41

42

43

44

45

46

47

48

49

50

51

52

53

54

55

56

57

58

59

60 